\title{
Acquired Factor XI Deficiency during SARS-CoV-2 Infection: Not Only Thrombosis
}

\author{
Giacomo Andreani ${ }^{10}$ Lorenzo Uscello ${ }^{2}$ Barbara Montaruli ${ }^{3}$ Antonio Briozzo ${ }^{2}$ Francesco Vitale ${ }^{2}$ \\ Marinella Tricarico $^{2}$ Luisa Arnaldi ${ }^{2}$ Stefania Marengo ${ }^{2}$ Claudio Norbiato ${ }^{2}$ \\ ${ }^{1}$ Department of Clinical and Biological Sciences, University of Turin, \\ Turin, Italy \\ 2 Department of Internal Medicine, A.O. Ordine Mauriziano, Turin, \\ Italy \\ Address for correspondence Giacomo Andreani, MD, Department of \\ Clinical and Biological Sciences, University of Turin, San Luigi Gonzaga \\ Hospital, Regione Gonzole 10, Orbassano 10043, Turin, Italy \\ (e-mail: giacomo.andreani@unito.it).
}

${ }^{3}$ Laboratory Analysis, A.O. Ordine Mauriziano, Turin, Italy

TH Open 2020;00:e233-e235.

An 80-year-old woman with a positive RT-PCR (reverse transcription polymerase chain reaction) for severe acute respiratory syndrome coronavirus 2 (SARS-CoV-2) on nasopharyngeal swab was admitted to our COVID-19 department during the pandemic with fever, dyspnea, and need for oxygen therapy; two large hematomas were present bilaterally in the axillary zones. Her past medical history included Crohn's disease diagnosed 30 years ago after perforation of the ascending colon, hypertension, bilateral hip replacement, appendectomy, and tonsillectomy; no history of bleeding complications was reported during or after surgical interventions or in the postpartum, and no history of menorrhagia or easy-bruising. One month and a half before admission, she underwent right knee replacement surgery with no complications, no blood units, or plasma transfusions were required. At that time complete blood count and screening clotting test were within normal range.

Investigations on admission were as follows: white blood cell 11,380/mm (Neu 10,790; Ly 240); hemoglobin $8 \mathrm{~g} / \mathrm{dL}$; mean corpuscular volume $89 \mathrm{fL}$; platelets $251,000 / \mathrm{mm}^{3} ; \mathrm{PTr}$ 1.16 (n.v. 0.80-1.21); PTTr 1.49 (n.v. 0.80-1.18); D-dimer 2,161 $\mu \mathrm{g} / \mathrm{L}$ (n.v. < 790); fibrinogen $455 \mathrm{mg} / \mathrm{dL}$ (n.v. 180-400); C-reactive protein $78.4 \mathrm{mg} / \mathrm{L}$ (n.v. $<5.0)$. A chest computed tomography scan outlined a picture of bilateral interstitial pneumonia with ground-glass areas and thickening of interstitium, consistent with a viral infection; moreover, the presence of hyperdense hematomas in the axillary zones was recorded (thickness $20-30 \mathrm{~mm}$ ), no active bleeding was detected. Antiretroviral therapy with darunavir and ritonavir was started; hydroxychloroquine was not administered for prolonged QTc on electrocardiogram. Enoxaparin 4000 IU/day was introduced for prophylaxis and continued until hospital discharge.

received

April 26, 2020

accepted

June 25,2020
DOI https://doi.org/ 10.1055/s-0040-1714696. ISSN 2512-9465.
The isolated prolonged PTTr (silica) was confirmed in day +5 and +7 from admission (1.30 and 1.42 , respectively), PTTr (ellagic acid, reagent sensible to factors VIII, IX, XI deficiency) was prolonged too, so a PTT MIX test was required: the PTTr MIX at time 0 was normal but PTTr MIX at 2 hours at $37^{\circ} \mathrm{C}$ was above the normal range, consistent with the presence of an inhibitor (-Table 1); the fXI activity was 37\% (n.v. 55-150) while fVIII, fIX, and fXII were in the normal range. Detection of antiphospholipid antibodies (lupus anticoagulant, anticardiolipin, and anti- $\beta 2$ glycoprotein I) resulted negative. The PTT MIX test and clotting factors activity was retested 3 days later and the presence of an acquired deficiency of fXI was confirmed. Patient was discharged in good clinical conditions more than 1 month after admission, no thrombotic or bleeding complications occurred during hospitalization.

Inhibitors against clotting factors generally occur in patients with severe congenital deficiencies who underwent periods of replacement therapy. Acquired factor inhibitors in the absence of congenital deficiency are rare events, among them the production of autoantibodies inhibiting fVIII is the most frequent acquired bleeding disorder. On the contrary, inhibitors against fXI have been reported only anecdotally in literature mostly associated to autoimmune disorders, that is, systemic lupus erythematosus, ${ }^{1}$ rheumatoid arthritis, ${ }^{2}$ Crohn's disease, ${ }^{3}$ membranoproliferative glomerulonephritis, ${ }^{4}$ or in association with malignancies, that is, chronic lymphocytic leukemia, ${ }^{5}$ gastrointestinal adenocarcinoma, ${ }^{3}$ and thymoma ${ }^{6}$; a case of transient acquired fXI deficiency after gynecological surgery has been reported. ${ }^{7}$ The risk of bleeding in conditions of fXI deficiency is relatively low and correlation between factor levels and symptoms is very poor; in these persons hemorrhage is usually provoked, exacerbated by trauma or surgical procedures. 8,9

\footnotetext{
(c) 2020 Georg Thieme Verlag KG Stuttgart · New York
}

License terms

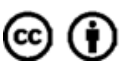


e234 Acquired Factor XI Deficiency during SARS-CoV-2 Infection Andreani et al.

Table 1 Coagulatory and inflammatory parameters

\begin{tabular}{|c|c|c|c|c|c|c|c|c|c|c|}
\hline & Unit & Ref. & March 17 & March 21 & March 23 & March 26 & April 7 & April 12 & April 18 & April 21 \\
\hline $\begin{array}{l}\text { Thrombin } \\
\text { time }\end{array}$ & Ratio & {$[<1.20]$} & & & 1.08 & & & & & \\
\hline $\begin{array}{l}\text { aPTTr } \\
\text { (silica) }\end{array}$ & Ratio & [0.80-1.18] & 1.49 & 1.30 & 1.42 & 1.55 & 1.40 & 1.30 & 1.30 & 1.24 \\
\hline $\begin{array}{l}\text { aPTT MIX } \\
\text { time } 0\end{array}$ & Ratio & [0.80-1.18] & & & 1.17 & 1.24 & & & & \\
\hline $\begin{array}{l}\text { aPTT MIX } \\
2 \mathrm{~h} 37^{\circ} \mathrm{C}\end{array}$ & Ratio & {$[0.80-1.18]$} & & & 1.20 & & & & & \\
\hline $\begin{array}{l}\text { aPTTr } \\
\text { (ellagic acid) }\end{array}$ & Ratio & [0.70-1.18] & & & 1.36 & & & & & \\
\hline Factor VIII & $\%$ & [50-200] & & & 120 & & & & & \\
\hline Factor IX & $\%$ & [65-140] & & & 101 & & & & & \\
\hline Factor XI & $\%$ & [55-150] & & & 37 & 38.5 & & & & \\
\hline Factor XII & $\%$ & [55-180] & & & 63 & & & & & \\
\hline D-dimer & $\mu g / L$ & {$[<790]$} & 2,161 & & 3,501 & & 2,471 & 2,004 & 2,183 & \\
\hline Fibrinogen & $\mathrm{mg} / \mathrm{dL}$ & [180-400] & 455 & 541 & 505 & & & 541 & 568 & \\
\hline CRP & $\mathrm{mg} / \mathrm{L}$ & {$[<5.0]$} & 78.4 & & & 55.6 & & 12.7 & 34.7 & \\
\hline
\end{tabular}

Abbreviations: aPTTr, activated partial thromboplastin time ratio; CRP, C-reactive protein.

In the classical chart of the intrinsic pathway of coagulation waterfall the fXIla activates the zymogen fXI which in turn activates fIX and so, through a series of enzymatic reactions, it conducts to thrombin formation. It is nowadays well documented that fXII has only a marginal role in the hemostasis in vivo, contributing more to inflammation and pathologic coagulation; in fact, XXI seems to be activated in a stronger way directly by thrombin, thus supporting and amplifying thrombin formation in loop. ${ }^{10}$ Moreover, it has also been shown how fXIa activates fXII after tissue factorinitiated coagulation (via extrinsic pathway). ${ }^{11}$ Maybe coagulation is not a waterfall but a whirlpool!

But fXI is not only a component of the coagulation pathway, it also participates to the process of contact activation by mean of the bradykinin-generating kallikrein-kinin system (KKS) (including fXII, prekallikrein PK, high molecular weight-kininogen $\mathrm{HK}$, and $\mathrm{C} 1$ esterase inhibitor C1INH) contributing in this way to several host-defenses and to the initial response to infection: in fact, the inflammatory response to viral infections is in part mediated by contact activation and it has already been demonstrated how hantavirus and herpes simplex virus 1 can lead to the activation of KKS pathway. ${ }^{12}$ The $\mathrm{XXI}$, together with $\mathrm{XXII}$, seems to have a pivotal role in this context. ${ }^{13}$ In a sepsis setting of fXI deficient mice, Bane et al have shown how a reduced early cytokine response and KKS activation conduct to a survival benefit compared with wild-type mice. ${ }^{11,14}$

Reconnecting to the case reported above, the reason for the occurrence of inhibitors production against fXI during SARSCoV-2 infection is still not clear to us, but maybe we can speculate that the inhibition of fXI could be a means of the immune system to try to turn off a sustained inflammatory overresponse against an infective agent which can otherwise conduct to deleterious effects for the host. Why not to consider this patient, with an autoimmune milieu (Crohn's disease), as evolutionary advantaged in this condition having the possibility to counterbalance the state of hypercoagulability and inflammation (the so-called, thromboinflammation ${ }^{15}$ )? Why not to act directly against $\mathrm{XXI}$, inhibiting it and on one side blocking the pathological coagulation loop with a mild risk of hemorrhage, as already demonstrated $^{16,17}$ and on the other side disrupting the mechanism driving to the uncontrolled inflammatory overresponse by blunting KKS and complement activation?

By our, at this point, everyday experience and from the still scanty literature in this regard it seems to us that patients with severe pneumonias by SARS-CoV-2 can develop a hypercoagulable condition driving to a higher risk for (micro)vascular thrombosis, still to demonstrate ${ }^{18-21}$; if true, considering the interface role of fXI in vascular thrombosis and inflammation, the development of therapies inhibiting this factor could be an intriguing leverage on which to act for trying to improve microvascular perfusion, reduce inflammation, and protect organ function during severe infections.

Conflict of Interest

None declared.

\section{References}

1 Wool GD, Treml A, Miller JL. Acquired factor XI deficiency and therapeutic plasma exchange. J Clin Apher 2018;33(03):427-430

2 Reece EA, Clyne LP, Romero R, Hobbins JC. Spontaneous factor XI inhibitors. Seven additional cases and a review of the literature. Arch Intern Med 1984;144(03):525-529

3 Kyriakou DS, Alexandrakis MG, Passam FH, et al. Acquired inhibitors to coagulation factors in patients with gastrointestinal diseases. Eur J Gastroenterol Hepatol 2002;14(12):1383-1387

4 McManus MP, Frantz C, Gailani D. Acquired factor XI deficiency in a child with membranoproliferative glomerulonephritis. Pediatr Blood Cancer 2012;59(01):173-175 
5 Goodrick MJ, Prentice AG, Copplestone JA, Pamphilon DH, Boon RJ. Acquired factor XI inhibitor in chronic lymphocytic leukaemia. J Clin Pathol 1992;45(04):352-353

6 Jethava Y, Alamelu J, Rangarajan S, Lang-Lazdunski L, van der Walt J, Fields P. Acquired agranulocytosis and factor XI deficiency in association with thymoma. J Clin Oncol 2011;29(20):e604-e606

7 Castaman G, Ruggeri M, Rodeghiero F. Acquired transitory factor XI inhibitor after gynaecological surgery. Haemophilia 2008;14 (03):643-644

8 Wheeler AP, Gailani D. Why factor XI deficiency is a clinical concern. Expert Rev Hematol 2016;9(07):629-637

9 Peyvandi F, Palla R, Menegatti M, et al; European Network of Rare Bleeding Disorders Group. Coagulation factor activity and clinical bleeding severity in rare bleeding disorders: results from the European Network of Rare Bleeding Disorders. J Thromb Haemost 2012;10(04):615-621

10 Emsley J, McEwan PA, Gailani D. Structure and function of factor XI. Blood 2010;115(13):2569-2577

11 Bane CE Jr, Ivanov I, Matafonov A, et al. Factor XI deficiency alters the cytokine response and activation of contact proteases during polymicrobial sepsis in mice. PLoS One 2016;11(04):e0152968

12 Long AT, Kenne E, Jung R, Fuchs TA, Renné T. Contact system revisited: an interface between inflammation, coagulation, and innate immunity. J Thromb Haemost 2016;14(03):427-437

13 Shatzel JJ, DeLoughery EP, Lorentz CU, et al. The contact activation system as a potential therapeutic target in patients with COVID-19. Res Pract Thromb Haemost 2020;4(04):500-505
14 Tucker EI, Verbout NG, Leung PY, et al. Inhibition of factor XI activation attenuates inflammation and coagulopathy while improving the survival of mouse polymicrobial sepsis. Blood 2012; 119(20):4762-4768

15 Jackson SP, Darbousset R, Schoenwaelder SM. Thromboinflammation: challenges of therapeutically targeting coagulation and other host defense mechanisms. Blood 2019;133(09):906-918

16 Chen W, Carvalho LP, Chan MY, Kini RM, Kang TS. Fasxiator, a novel factor XIa inhibitor from snake venom, and its site-specific mutagenesis to improve potency and selectivity. J Thromb Haemost 2015;13(02):248-261

17 Büller HR, Bethune C, Bhanot S, et al; FXI-ASO TKA Investigators. Factor XI antisense oligonucleotide for prevention of venous thrombosis. N Engl J Med 2015;372(03):232-240

18 Magro C, Mulvey JJ, Berlin D, et al. Complement associated microvascular injury and thrombosis in the pathogenesis of severe COVID19 infection: a report of five cases. Transl Res 2020;220:1-13

19 Terpos E, Ntanasis-Stathopoulos I, Elalamy I, et al. Hematological findings and complications of COVID-19. Am J Hematol 2020;95 (07):834-847

20 Klok FA, Kruip MJHA, van der Meer NJM, et al. Incidence of thrombotic complications in critically ill ICU patients with COVID-19. Thromb Res 2020

21 Panigada M, Bottino N, Tagliabue P, et al. Hypercoagulability of COVID-19 patients in intensive care unit: a report of thromboelastography findings and other parameters of hemostasis. J Thromb Haemost 2020. Doi: 10.1111/jth.14850 